\title{
MISSÕES DE PAZ E RELAÇÕES CIVIS- MILITARES: REFLEXÕES SOBRE O CASO BRASILEIRO ${ }^{1}$
}

\author{
Adriana A. Marques²
}

\section{Introdução}

O encerramento da Missão das Nações Unidas para Estabilização do Haiti (MINUSTAH), em outubro de $20 \mathrm{I}^{3}$, desencadeou uma onda de reflexões políticas e acadêmicas acerca do legado da participação brasileira neste evento que durou i3 anos e mobilizou cerca de 37 mil militares.

Diplomaticamente, a MINUSTAH foi considerada pelo governo brasileiro um importante instrumento de política externa que possibilitou ao país exercer um maior protagonismo no cenário internacional, sobretudo na América Latina e Caribe (Amorim 2016) e qualificar-se como provedor de paz perante a Organização das Nações Unidas (Jungmann 20I7). O Congresso Nacional, que manifestou algumas reticências ao envio de tropas brasileiras para o Haiti, especialmente durante a apreciação da Exposição de Motivos dos ministros de Relações Exteriores e da Defesa sobre esta matéria em 20044,

\footnotetext{
I As ideias apresentadas neste artigo foram discutidas previamente em três oportunidades, na XIII Conferência Internacional da Brazilian Association Studies em 20I6, no IX Congresso da Associação Latino-Americana de Ciência Política em 20I7 e no XI Encontro da Associação Brasileira de Ciência Política em 20I8. A participação nos três eventos foi viabilizada pelo projeto Cenários Internacional e Regional de Segurança e Defesa: uma abordagem Civil Militar, financiado pelo Conselho Nacional de Desenvolvimento Científico e Tecnológico e pelo Ministério da Defesa.

2 Professora Adjunta do Bacharelado em Defesa e Gestão Estratégica Internacional da Universidade Federal do Rio de Janeiro. E-mail: a.a.marques@irid.ufrj.br

3 A MINUSTAH foi substituída pela Missão das Nações Unidas de apoio à Justiça no Haiti (MINUJUSTH) que terá como objetivo apoiar o fortalecimento das instituições públicas e o Estado de Direito no país.
}

4 Okaddo (20I7) mapeou a atuação da Comissão de Relações Exteriores e Defesa Nacional da 
ecoou a narrativa oficial do poder executivo acerca da sucesso da missão (Brasil 20I7).

Na perspectiva dos militares, a MINUSTAH permitiu que oficiais e graduados brasileiros das três Forças Armadas pudessem ser imersos em um ambiente operacional real. Organizacionalmente, o Centro Conjunto de Operações de Paz do Brasil (CCOPAB) beneficiou-se diretamente da experiência brasileira no Haiti, tendo evoluído de uma estrutura vinculada ao Exército brasileiro a um órgão de inspeção da ONU na acreditação de forças de paz (Teixeira 20I7).

A produção acadêmica sobre missões de paz no Brasil cresceu exponencialmente desde que o país assumiu o comando do contingente militar da MINUSTAH. Abdenur, Kuele, Folly e Macedo (20I7) constataram, a partir de um levantamento no portal de periódicos da CAPES, que foram produzidos 35 livros, artigos e monografias sobre operações de paz no Brasil de I990 a 2003. Já no período subsequente, de 2004 a 20I7, a produção bibliográfica sobre o tema alcançou a marca de 4I 8 trabalhos5.

A literatura internacional sobre a participação brasileira em operações de paz também aumentou significativamente na última década ${ }^{6}$ e, no que diz

Câmara dos Deputados (CREDN) nas questões relativas à MINUSTAH e constatou que após um embate inicial entre membros da comissão que se opunham ao envio de tropas brasileiras ao Haiti e os que apoiavam a iniciativa do governo brasileiro, a CREDN pouco opinou a respeito do desempenho das tropas brasileiras no Haiti.

5 Segundo Abdenur, Kuelle, Folly e Macedo (20I7) a literatura produzida no Brasil sobre a MINUSTAH concentra-se no processo decisório que levou o governo brasileiro a aceitar chefia militar da missão e nas relações dessa decisão com a tentativa brasileira de expandir o seu soft power, de consolidar uma posição de liderança regional, de fortalecer a posição do país na cooperação sul-sul, de se contrapor aos Estados Unidos, de garantir um assento permanente no Conselho de Segurança da ONU e apresentar uma alternativa ao princípio da Responsabilidade de Proteger vigente nesta organização. Em relação a atuação dos militares brasileiros no Haiti, a literatura nacional enfoca a parte operacional da missão, as atividades que foram executadas pelas tropas brasileiras e quais os possíveis retornos dessa experiência tanto em termos de aprendizagem organizacional para novas missões de paz quanto no que concerne à aplicação desse aprendizado no Brasil. Esse levantamento bibliográfico também evidencia algumas tendências na produção de conhecimento sobre as Forças Armadas brasileiras que já haviam sido apontadas por Marques e Fuccille (20I5), qual seja, a participação brasileira na MINUSTAH renovou o interesse acadêmico sobre o aparelho militar, a nova geração de estudos sobre esse tema não está mais concentrada nas universidades do eixo São Paulo-Rio-Brasília e há pesquisadores e pesquisadoras em vários níveis de formação acadêmica trabalhando de forma integrada sobre questões internacionais e de defesa.

6 A literatura internacional sobre a participação brasileira em operações de paz, assim como a literatura brasileira, é extensa e uma revisão bibliográfica sobre esse tema fugiria ao escopo deste artigo. Eric Cezne (20I6) fez uma discussão detalhada da literatura internacional sobre o Brasil em operações de paz em sua dissertação de mestrado. 
respeito ao legado da atuação de nossas tropas no Haiti, um ponto em particular interessa a discussão que será feita neste artigo, a chamada conexão Porto-Príncipe-Rio de Janeiro (Hirst e Nasser 20I4:04), ou seja, em que medida a experiência das Forças Armadas em ações de controle da ordem pública no Brasil influencia a atuação das tropas brasileiras no exterior e vice-versa? A resposta a essa pergunta não é unânime e relaciona-se diretamente com outra questão bem menos estudada tanto na literatura nacional quanto na literatura internacional e que será discutida a seguir: as interconexões entre a participação dos militares em missões de paz e as relações civis-militares, tendo em vista a participação cada vez mais rotineira das Forças Armadas brasileiras em missões de Garantia da Lei e da Ordem (GLO) e a grave crise política que o país atravessa.

Para a elaboração do artigo foi realizada uma revisão bibliográfica da literatura que discute os nexos entre a participação dos militares em missões de paz e o relacionamento entre as Forças Armadas e outros setores do Estado no âmbito doméstico, a literatura que discute as relações civis-militares no Brasil e a coleta de fontes primárias, como documentos governamentais, matérias publicadas em jornais e revistas de circulação nacional e entrevistas concedidas pelo comandante do Exército brasileiro e pelos comandantes brasileiros da MINUSTAH a veículos da imprensa. Ademais, foram realizadas doze entrevistas ${ }^{7}$ semiestruturadas, individuais e em grupo, em Brasília e no Rio de Janeiro com graduados e oficiais brasileiros das três Forças Armadas que participaram de missões de paz em Angola, no Haiti e no Líbano ${ }^{8}$ e entrevistas em profundidade com os comandantes militares da MINUSTAH?.

7 Todas as entrevistas utilizadas como fontes primárias neste artigo foram realizadas no âmbito do projeto Transformações da profissão militar no Brasil e na Argentina: a perspectiva das Ciências Sociais, financiado pela Coordenação de Aperfeiçoamento de Pessoal de Nível Superior.

8 As identidades dos entrevistados individualmente ou no grupo focal foram preservadas e as informações obtidas nas entrevistas foram utilizadas exclusivamente para fins acadêmicos no âmbito do projeto Transformações da profissão militar no Brasil e na Argentina: a perspectiva das Ciências Sociais. Os depoimentos dos comandantes militares da MINUSTAH foram doados ao acervo do Centro de Pesquisa e Documentação de História Contemporânea do Brasil da Fundação Getulio Vargas.

9 Os comandantes militares da MINUSTAH foram o General de Exército Heleno Ribeiro Pereira (2004-2005), o General de Divisão Urano Teixeira da Matta Bacellar (2005-2006), o General de Exército José Elito Carvalho Siqueira (2006-2007), o General de Divisão Carlos Alberto dos Santos Cruz (2007-2009), o General de Divisão Floriano Peixoto Vieira Neto (2009-20ıо), o General de Divisão Luiz Guilherme Paul Cruz (20I0-20II), o General de Divisão Eduardo Ramos Baptista Pereira (20II-20I2), o General de Divisão Fernando Rodrigues Goulart (20I2-20I3), o General de Exército Edson Leal Pujol (20I3-20I4), o General de Divisão 
O artigo está organizado em três seções além desta introdução. A segunda seção revisa a literatura internacional e brasileira que discute as conexões entre a participação de um país em missões de paz e a estabilidade das relações civis-militares, apontando as limitações do argumento segundo o qual a participação em missões de paz teria um efeito reformador sobre as instituições militares dos países africanos e latino-americanos que contribuem substantivamente com tropas para a ONU e discute algumas especificidades do caso brasileiro. A terceira seção mapeia as percepções dos militares brasileiros sobre a participação em missões de paz enfocando seus reflexos para as relações civis-militares. Por fim, serão feitas algumas considerações finais sobre este tema.

\section{As missões de paz e as relações civis-militares na perspecti- va acadêmica}

A participação em missões de paz é uma das principais tarefas executadas pelas forças armadas contemporâneas ${ }^{10}$ (Matei 20I2). Desde a criação da Organização das Nações Unidas (ONU), em I945, até os dias atuais, o número de missões de paz realizadas sob o mandato da organização aumentou exponencialmente, especialmente após o final da Guerra Fria. Além disso, o perfil dessas missões mudou bastante ao longo das décadas. Da primeira missão de paz, em 1948, quando os observadores militares foram enviados ao Oriente Médio para monitorar o acordo de armistício entre Israel e seus vizinhos árabes, à polêmica decisão do Conselho de Segurança da ONU que autorizou a utilização de uma brigada de intervenção com tropas de forças especiais e a missão de "neutralizar" os grupos armados na Missão das Nações Unidas na República Democrática do Congo (MONUSCO), em $2013^{\text {II }}$, houve

José Luiz Jaborandi Júnior (20I4-20I5) e o General de Divisão Ajax Porto Pinheiro (20I5-20I7). Dois comandantes da MINUSTAH já faleceram, o General de Divisão Urano Teixeira da Matta Bacellar e o General de Divisão José Luiz Jaborandi Júnior.

Io Cristiana Matei elenca as seis principais tarefas executadas pelas Forças Armadas contemporâneas: I-travar e estar preparada para travar guerras, 2- travar e estar preparada para travar guerras intraestatais, 3- contraterrorismo, 4- apoio às forças policiais no combate à criminalidade, 5- missões de paz, 6- assistência humanitária (Matei 20I2).

II A este respeito, vale conferir as posições do Brasil, Argentina, Chile e Uruguai sobre o mandato da MONUSCO. No caso brasileiro chama a atenção o fato de que se no início da MINUSTAH houve algum posicionamento crítico da CREDN em relação ao uso da força pelas tropas brasileiras no Haiti, em 20I3, enquanto a ONU debatia a ampliação do uso da força de suas tropas para impor a paz no Congo no âmbito do Capítulo VII de sua carta, um tema que interessa diretamente ao Brasil que por força da Constituição de I988 pode participar apenas de missões de manutenção da paz, não houve qualquer manifestação da CREDN a esse respeito. 
uma importante extensão no escopo dos mandatos e mudanças substantivas na natureza das operações de paz, que precisam lidar com um grande número de tarefas técnicas e assistenciais em ambientes cada vez mais complexos.

No entanto, apesar de todas essas mudanças, cabe ressaltar que a observação do secretario geral das Nações Unidas, Dag Hammarskjöld, nos idos da década de I950: "as operações de paz não são tarefas para soldados mas apenas os soldados podem executá-las" (Moskos i976:139), permanece atual.

Em relação à participação de tropas estadunidenses e europeias em operações de paz, Charles Moskos (I976), argumentava que a participação dos militares em missões de paz, que não tinham como objetivo principal eliminar o inimigo, traria grandes benefícios para o relacionamento entre os militares e os outros setores do Estado e da sociedade ao longo do tempo, uma vez que esse tipo de missão exigiria das forças armadas uma capacidade de negociação que os conflitos convencionais não contemplavam.

Moskos construiu seu argumento a partir das ideias expostas por Morris Janowitz em sua obra seminal $O$ soldado profissional. Analisando o contexto estratégico em que as tropas estadunidenses poderiam operar durante o auge da Guerra Fria, Janowitz ( 1967 ) advertia que os militares deveriam estar preparados para combater tanto em uma guerra nuclear quanto em uma guerra convencional de resistência. Essas duas formas de guerra, de acordo com o autor, exigiriam das forças armadas uma maior capacidade de negociação política e flexibilidade. Como o uso da força nas relações internacionais havia se alterado significativamente, seria importante que os militares incorporassem em seus requisitos profissionais capacidades que até então eram exigidas apenas de forças policiais como o comprometimento com o uso mínimo da força e a procura de relações estáveis ao invés da vitória:

“a concepção policial engloba todo o âmbito de poder nas organizações mil-

Okado (20I7) relata que tampouco houve um debate substantivo na CREDN sobre o envio de tropas brasileiras para o Líbano em 20ıo. O que se discute aqui não é a conveniência de o país participar de missões de paz mas o claro desinteresse da CREDN em discutir e supervisionar os assuntos referentes a essa temática. O comportamento errático legislativo brasileira em relação aos temas de defesa foi analisado por Oliveira (2005) e seu diagnóstico ainda permanece atual. Pion-Berlin e Trinkunas (2007) estendem o diagnóstico de Oliveira (2005) para toda a América Latina quando se referem ao déficit de atenção dos políticos da região em relação à política de defesa. As pautas das reuniões da CREDN em 2013 podem ser consultadas em: http://www2. camara.leg.br/atividade-legislativa/comissoes/comissoes-permanentes/credn/reunioes/ pesquisa_reunioes_comissao.

O posicionamento brasileiro e dos demais países sul-americanos que contribuem com tropas para missões de paz sob o mandato da ONU foram analisadas por Mónica Hirst (2016) no livro La presencia de Argentina em Haiti.

\section{Austral: Revista Brasileira de Estratégia e Relações Internacionais} v.7, n.14, Jul./Dez. 2018 
itares. Na extremidade superior estão as armas de destruição em massa; as de aplicação flexível e especializada encontram-se na extremidade inferior, onde se acham também os especialistas em programas de ajuda militar, em operações paramilitares, em guerrilha e contraguerrilha. Equacionar a manipulação de armas de alto poder destrutivo com a estratégia e as de pequeno poder destrutivo com as táticas tem sido, e continua a ser, fonte de confusão profissional e pública. A concepção policial reconhece haver dimensões estratégicas e táticas em cada uma das extremidades da escala. As táticas da intimidação estratégica, por exemplo, exigem decisões diárias que variam desde relações comunitárias em bases ultramarinas até a determinação de momentos propícios para declarações político-militares de líderes nacionais. Por outro lado, as decisões estratégicas relativas à guerra limitada envolvem políticas de amplas consequências com referência ao tamanho, controle e distribuição de unidades militares.

Não é mais possível à oficialidade, se esta deseja estar organizada eficazmente para intimidação estratégica e para a guerra limitada atuar segundo premissas "de guerra" e "de paz". Como a concepção de uma força policial elimina a distinção entre um estamento militar de paz e de guerra ela se aproxima do conceito de policiamento" (Janowitz I967, 400).

Décadas mais tarde, Charles Moskos chamaria este novo profissional de perfil negociador - cujo surgimento Janowitz identificara ainda durante a Guerra Fria - de militar-estadista, definindo-o como um oficial qualificado para lidar com a mídia e apto a atuar no complexo ambiente da diplomacia internacional (Moskos 2000).

Na contemporaneidade, as missões de paz são o principal terreno onde as habilidades diplomáticas dos militares são exercitadas. Giuseppe Caforio (2007) apresentou os resultados de uma série de surveys realizados entre a década de 1990 e o início do novo milênio com militares dos Estados Unidos e alguns países da Europa ocidental. Estes estudos mostravam que a inserção cada vez maior de militares estadunidenses e europeus em tropas multinacionais teria um duplo significado para as forças armadas desses países: ao mesmo tempo em que a convivência e a troca de experiências com outras organizações militares tenderia a padronizar certos comportamentos organizacionais, o contato com tropas estrangeiras tenderia a reforçar alguns valores tradicionais nas equipes multinacionais como o patriotismo, disciplina, senso de responsabilidade e dedicação (Caforio 2007).

Os resultados dos surveys realizados por Caforio mostram que para as forças armadas de países com democracias mais robustas, a experiência de operar em tropas multinacionais tende a reforçar alguns valores militares tradicionais nos membros das equipes, além de contribuir para o aprimoramento de novas capacidades (Caforio 2007). Porém, uma das principais 
características das missões de paz contemporâneas é a participação cada vez maior de tropas provenientes de países latino-americanos, asiáticos e africanos em substituição a tropas estadunidenses e de seus aliados da OTAN.

Em um primeiro momento, a literatura internacional destacou os aspectos positivos da participação em missões de paz no processo de socialização desses militares, tornando-os mais profissionais e democráticos. O contato entre as tropas estadunidenses e de seus aliados com tropas de países que haviam saído de regimes autoritários e tinham pouca experiência internacional, dentro dessa perspectiva, exerceria um efeito reformador sobre as instituições militares e os indivíduos que participassem de equipes multinacionais. Este potencial efeito reformador também se estenderia ao plano das relações civis-militares, contribuindo para reforçar a subordinação dessas forças armadas ao poder civil em seus países de origem.

Segundo Michel Desch, a participação em missões de paz traria grandes benefício aos países que estivessem passando por uma transição de um regime autoritário para um regime democrático pois seria mais fácil controlar os militares enquanto eles estivessem servindo em missões no exterior (Desch I999, I2).

Este efeito reformador da participação em missões de paz também é enfatizado por Pion-Berlin e Arceneaux para os quais militares orientados para missões externas seriam mais profissionais no sentido clássico do termo e tenderiam a se envolver menos em assuntos domésticos (Pion-Berlin e Arceneaux 2000).

Em um artigo mais recente sobre o cumprimento de missões militares na América Latina, Pion-Berlin aponta que as missões de paz são um desafio para os militares pois exigem que eles desempenhem vários papéis. Embora muitos desses papéis estejam além do seu alcance profissional, eles ainda são bastante gratificantes para os militares latino-americanos. Há um fator de prestígio associado a estas missões. A participação em operações de paz também tem sido associada à formação profissional avançada e à satisfação de requisitos de promoção e muitos militares redescobrem o seu propósito seguindo estas missões (Pion-Berlin 2012, 637).

Magnus Lundgren aprofunda os argumentos apresentados pelos autores acima, especialmente os de Michael Desch, a partir do que compreende ser um comportamento racional dos militares de países pobres que dependem financeiramente da participação em missões de paz da ONU para equilibrarem seus orçamentos de defesa. Esses militares, segundo o autor, evitariam atos ostensivos de insubordinação militar e tentativas de golpe para poderem continuar participando de missões de paz, uma vez que a ONU prefere contar com países que tenham relações civis-militares estáveis para compor as suas 
tropas (Lundgren 20I8).

Maggie Dwyer, por sua vez, discute as limitações do modelo teórico que defende o efeito reformador da participação em missões de paz em seu estudo de caso sobre os motins liderados por soldados egressos de missões da ONU em países do oeste da África. De acordo com a autora, ocorreram ao menos dez motins na região desde I99I relacionados a queixas de soldados que haviam participado de missões de paz. Os países do oeste da África contribuem substantivamente com tropas para as missões da ONU mas isso parece ter um efeito bastante limitado na reforma da instituições militares africanas. Os motins estudados por Dwyer resultam de uma interação entre queixas materiais e um sentimento de injustiça, em geral essas questões estão relacionadas à corrupção dos oficiais que lideram as tropas e ficam com parte dos salários dos subordinados (Dwyer 20I5).

Tendo em vista as dificuldades de generalização verificadas nos primeiros estudos que discutiam o potencial reformador da participação em missões de paz, Levin, MacKay, Nasirzadeh e Sealey propõem um aperfeiçoamento da hipótese do peacekeeper democrático. Relacionando os reflexos da participação em missão de paz no plano das relações civis-militares ao tipo de regime político do país estudado, os autores concluem que os países com democracias robustas seriam os que mais se beneficiariam da participação em missões de paz, já os países autoritários ou com democracias frágeis pouco se beneficiariam dessa atividade. A transferência de fundos e prestígio da ONU para as forças armadas de países não democráticos ou instáveis politicamente poderia inclusive potencializar a possibilidade de um golpe militar nesses lugares, desestabilizando-os ao invés de contribuir para a reforma de suas instituições militares (Levin et al. 20I7).

No que concerne à literatura sobre a participação brasileira em missões de paz, as expectativas dos analistas não diferiam daquelas apresentadas pela literatura internacional até o advento da MINUSTAH. Clóvis Brigagão, em um texto de I999, defendia que a nova geração de soldados brasileiros treinados após a participação em missões de paz teriam uma nova visão sobre a prevenção de conflitos e governos civis (Brigagão I999).

Já a bibliografia mais recente sobre o caso brasileiro, em especial o livro de Arturo Sotomayor The Mith of Democratic Peacekeeper, questiona o possível efeito reformador da participação de missões de paz. Para Sotomayor, a participação do Brasil em missões desta natureza não teve os efeitos esperados pelos analistas que estudam o tema. Seu argumento é que os militares brasileiros não só replicam como reforçam seus entendimentos organizacionais e práticas domésticas nas missões de paz das quais participam. Ele analisou a participação de tropas brasileiras na África e no Haiti para corroborar 
sua tese (Sotomayor 20I4).

Sobre a participação de tropas brasileiras em Moçambique e Angola na década de ı990, Sotomayor argumenta que o os militares brasileiros viam as missões de paz na África como uma extensão de missões subsidiárias, principalmente as ações cívico-sociais (ACISO), eles que realizavam no Brasil. O autor identifica nesta percepção a influência da atuação das Forças Armadas na Amazônia. No que tange à preparação das tropas para as missões que seriam desempenhadas sob o mandato da ONU, havia o entendimento de que os militares treinados para operar na Amazônia estariam capacitados para operar na África, por este motivo grande parte do contingente empregado nas missões de Verificação das Nações Unidas em Angola e na Operação das Nações Unidas em Moçambique foi recrutado em Manaus e outros lugares da Amazônia. Os militares, segundo Sotomayor, levaram para a África as práticas que eram consideradas efetivas no Brasil para lidar com as carências de uma população que vive em um ambiente onde o Estado se faz presente em boa medida através das instituições militares ${ }^{12}$ e foram pouco influenciados por esta experiência internacional. (Sotomayor 20I4:82-84).

Em relação ao argumento de Sotomayor, é necessário ponderar que o Brasil não tinha na década de I990 um centro de treinamento voltado para as operações de paz onde a experiência organizacional adquirida na África pudesse ser processada e disseminada nas tropas. Além disso, a participação das Forças Armadas brasileiras em atividades de assistência social e apoio ao desenvolvimento tem raízes históricas profundas (D’Áraújo 20I0) e cresceu significativamente a partir dos anos 2000 (Mathias, Campos e Santos 20I6) dificultando a disseminação de qualquer benefício organizacional que a participação em uma missão no exterior pudesse trazer.

Já no caso das tropas enviadas para o Haiti, Sotomayor sustenta que as estratégias utilizadas pelos militares brasileiros para pacificar as favelas onde atuaram seriam as mesmas utilizadas no Brasil logo a performance de nossas tropas no exterior ao invés de promover algum tipo de reforma das instituições militares estaria reforçando as práticas já adotas adotadas no ambiente doméstico. Um exemplo lapidar neste sentido seria o pedido de tropas militares para pacificar as favelas do Complexo do Alemão feito pelo então governador do Rio de Janeiro Sérgio Cabral. Na ocasião, Cabral utilizou o desempenho das tropas brasileiras nas favelas do Haiti para justificar sua demanda de militarização dos problemas de segurança pública no Rio de Janeiro (Sotomayor 2014, 88).

\footnotetext{
I2 Sobre a importância material e simbólica que os militares brasileiros atribuem à Amazônia ver: Marques (2007).
}

250 Austral: Revista Brasileira de Estratégia e Relações Internacionais v.7, n.14, Jul./Dez. 2018 
Jorge Zaverucha também questiona a tese do efeito reformador da participação em missões de paz. Recuperando a letra de uma canção famosa de Caetano Veloso e Gilberto Gil, Zaverucha afirma que "o Haiti é aqui" (Zaverucha 2005), ou seja, as tropas brasileiras estariam treinando no Haiti para serem empregadas no combate à criminalidade no Brasil e o emprego rotineiro de tropas militares para combater a violência urbana no país seria um dos indicadores de que a democracia no Brasil ainda é frágil (Zaverucha 2008).

A conexão Porto Príncipe-Rio de Janeiro está no centro do debate sobre o legado da participação brasileira na MINUSTAH. As primeiras análises que tratam das experiências entrecruzadas nos dois casos datam de 2014 . Além de Sotomayor (20I4), Hirst e Nasser chamaram a atenção para este fenômeno. Os autores registraram que aproximadamente 60\% das tropas militares empregadas na favela da Maré em 20 Io era formada por egressos da MINUSTAH e que projetos do Viva Rio voltados para as favelas cariocas estariam sendo replicados em Bel Air e Cité Soleil (Hirst; Nasser, 20I4). De acordo com Sotomayor (20I4), o Viva Rio foi a organização não-governamental que trabalhou mais de perto com os brasileiros no Haiti.

Kristian Hoelscher e Per Norheim-Martinsen por sua vez alertam para as possíveis consequências indesejáveis da utilização rotineira de peacekeepers nas missões de Garantia da Lei e da Ordem. Para os autores, a atuação dos militares nas favelas cariocas entrecruza a experiência no Haiti com uma longa tradição militar latino-americana de controle da ordem pública e isso poderia dificultar a consolidação da democracia no Brasil (Hoelscher e Norheim-Martinsen 2014).

Siman e Santos (20I8) apresentam um argumento similar quando analisam a influência do binômio segurança e desenvolvimento no imaginário dos militares brasileiros e como isso se expressa na atuação das tropas brasileiras quando elas estão cumprindo missões de Garantia da Lei e da Ordem e participando de missões de paz.

Haring reconhece os efeitos sinérgicos que as duas experiências, a missão de paz no Haiti e a missão de Garantia da Lei e da Ordem no Rio de Janeiro, têm para as tropas mas conclui que em um futuro próximo, a aprendizagem organizacional que a missão no Haiti proporcionou às Forças Armadas deverá ser aplicada no controle da ordem pública no Brasil e não em novas missões de paz como desejam os diplomatas e militares (Haring 20I6, I58).

Uma questão importante perpassa todas as análises que discutem a conexão ou a retroalimentação entre a atuação dos militares brasileiros em missões de paz e em missões subsidiárias no Brasil: o maior envolvimento em operações de paz não diminuiu a participação das Forças Armadas em ati- 
vidades subsidiárias no país como previam os primeiros estudos sobre esta temática, ao invés disso, verificou-se um aumento significativo do emprego das tropas que retornaram do Haiti em operações de Garantia da Lei e da Ordem.

A tendência à banalização do uso da Garantia da Lei e da Ordem, já criticada pelo comandante do Exército, general Eduardo Villas Bôas (Monteiro 20I8), associada à grave crise política que o Brasil atravessa desde 2016 , com a deposição da presidenta Dilma Vana Rousseff, criou as condições para uma situação sui generis no final do mês de maio de 20I8. Enquanto o governo federal decretava pela primeira vez uma operação de Garantia da Lei e da Ordem em todo o território nacional para desobstruir as vias públicas federais e tentar dar uma solução à greve dos canhoneiros que se estendia por vários dias com consequências graves para todo o país (Brasil 20I8), parte dos caminhoneiros em greve incluiu o pedido de uma intervenção militar temporária na pauta de reivindicações da categoria para retornar ao trabalho (Betim 20I8).

Este episódio, reverbera em certa medida as lições da literatura internacional sobre os efeitos colaterais da participação de países instáveis politicamente em missões de paz, mas no caso brasileiro são necessárias algumas considerações. Quando o Brasil assumiu o comando militar da MINUSTAH, o país vivia um período de estabilidade política e a decisão de participar mais efetivamente de missões de paz da ONU estava inserida em um projeto de ampliação do protagonismo brasileiro no cenário internacional (Amorim 20I6) no entanto, quando a crise da segurança pública se intensificou, o bom desempenho das tropas no Haiti passou a ser visto pela classe política como um ativo importante para o controle da ordem pública e o recurso às operações de Garantia da Lei e da Ordem tornou-se cada vez mais frequente, reforçando o processo de retroalimentação entre as missões que as tropas brasileiras desempenhavam no exterior e em território nacional.

A deposição da presidenta Dilma Rousseff intensificou uma reversão de expectativas no que concerne ao papel que as Forças Armadas brasileiras devem desempenhar. Se até o governo Rousseff havia ao menos um projeto de articulação entre a política externa e a política de defesa, no qual os militares orientariam suas missões cada vez para a defesa dos interesses do país no exterior (Alsina 20I7), no governo Temer esta tendência foi interrompida e as Forças Armadas passaram a atuar rotineiramente em operações de combate à criminalidade sem a expectativa de uma missão relevante no exterior ${ }^{13}$.

Dentro de um quadro de estabilidade democrática não havia indicado-

I3 Havia a expectativa de que o Brasil enviasse tropas para a missão de paz na República CentroAfricana em 2018 mas o governo Temer rejeitou a proposta da ONU e decidiu priorizar a intervenção federal na área de segurança pública no Rio de Janeiro (Góes 20I8).

252 Austral: Revista Brasileira de Estratégia e Relações Internacionais v.7, n.14, Jul./Dez. 2018 
res visíveis de que a utilização rotineira de tropas militares em operações de Garantia da Lei e da Ordem pudesse ter um efeito negativo sobre a qualidade da democracia brasileira, mas o acirramento da crise política colocou essa possibilidade na ordem do dia já que o grau de dependência política das Forças Armadas vigente no governo de Michel Temer só encontra paralelo no governo de José Sarney (I985-I990). Eliézer Rizzo de Oliveira definiu o padrão de relações civis-militares neste período como tutela militar:

Tenho empregado o conceito de tutela militar para designar uma situação na qual um governo politicamente frágil de apoio partidário e parlamentar encontra nas Forças Armadas a fonte primeira de sua estabilidade ao preço de preservar os traços básicos da experiência militar recente: um grau elevado de autonomia política do aparelho militar quanto à definição da estratégia nacional; o exercício da função interventora; um grau por vezes disfuncional, porque extremamente abrangente, de interferência dos ministros militares em assuntos extramilitares; a afirmação do Exército como a força por excelência para estabilidade do regime (Oliveira 1994).

Mas se a conjuntura política atual é semelhante àquela vivida durante o governo de José Sarney, cabe ressaltar que o Exército hoje tem um padrão de comportamento diferente daquele verificado no início da Nova República (Oliveira 2005). A contrariedade do atual comandante do Exército em assumir funções que extrapolam a esfera militar difere frontalmente da desenvoltura com que o general Leônidas Pires Gonçalves assumia sua função tutelar sobre o presidente da República na década de I980, o que suscita algumas questões que serão tratadas a seguir.

\section{As missões de paz e as relações civis-militares na perspectiva dos militares}

No livro $A$ invenção do Exército Celso Castro argumenta que a defesa da Amazônia brasileira contra a cobiça internacional havia se tornado um importante elemento identitário para o Exército brasileiro a partir da década de I990 e isso implicava uma mudança doutrinária importante. Após décadas se preparando prioritariamente para combater um inimigo interno, a defesa da Amazônia apontava para o preparo contra um inimigo externo, o que tinha consequências importantes para o padrão de relações civis-militares no país (Castro 2002).

Quando o Brasil assumiu o comando militar da Missão das Nações 
Unidas para Estabilização do Haiti (MINUSTAH) surgiu a possibilidade do emprego das Forças Armadas brasileiras em uma missão orientada para o exterior e inserida em um projeto de inserção internacional do país na América Latina e no Caribe. Neste contexto, a participação em missões de paz poderia se constituir em um elemento identitário tão importante quanto foi a Amazônia na década de I990, atuando como um símbolo mobilizador da identidade militar no século XXI.

O Brasil passou mais de duas décadas sem enviar tropas para missões da ONU. Após permanecer dez anos em Suez (I957-1967), o país retomou sua participação com contingentes em missões de paz enviando tropas para Moçambique em i994. Durante esse hiato, a natureza das operações de paz mudou substantivamente e os militares brasileiros tiveram que se adaptar aos novos tempos no Brasil e no âmbito internacional.

A participação brasileira em missões de paz sob o mandato das Nações Unidas cresceu substancialmente a partir dos anos 2000, principalmente quando o Brasil assumiu o comando da MINUSTAH em 2004, no entanto, até 20ıo, o Brasil ainda não contava com um centro de preparação voltado para o treinamento de militares que iriam participar de operações de paz (Teixeira 20I7). Nas palavras de um militar que participou do contingente brasileiro na missão de paz em Moçambique na década de ı990:

“(...) nós tivemos que reaprender o que significava uma missão de paz. Nós não tínhamos memória, a última missão havia sido em Suez, em I967, não existia como hoje um centro de operações de paz, não existia lições aprendidas, não existia nada disso. Nossas atividades foram baseadas nos cadernos de instrução, no que existia para o adestramento regular da tropa, não especificamente para operações de paz. Nós tivemos que fazer uma adaptação do que existia para o adestramento interno, ou seja, de atividades que eram realizadas dentro do país e adaptar para operações de paz. Então foi uma reinvenção (...) (Entrevista I 20I6)".

Este processo de reinvenção na maneira de as Forças Armadas brasileiras operarem no exterior foi acompanhado de medidas administrativas que visavam internalizar os procedimentos e normas vigentes nas missões de paz, o que produziu modificações no comportamento das tropas no terreno. Em 2005 foi criado o Centro de Instrução de Operações de Paz que iniciou suas atividades com a incumbência de conduzir a preparação do terceiro contingente brasileiro enviado para a missão no Haiti e, finalmente, em 20Io, foi criado o Centro Conjunto de Operações de Paz do Brasil (CCOPAB) que assumiu a missão de preparar militares e civis brasileiros e estrangeiros a serem 
enviados para missões de paz (Teixeira 20I7).

Concomitantemente à adaptação às normas internacionais vigentes nas operações de paz, a participação neste tipo de missão também permite testar a capacidade dos militares nelas envolvidos e posicioná-los em uma escala que reproduz a divisão de poder entre os países na arena internacional.

Um oficial que esteve no primeiro contingente de brasileiros designados para operar em uma brigada espanhola relata que no começo da missão eles foram "colocados de lado" e a cada dia tinham que provar que eram capazes de cumprir as missões "em nível europeu" O militar atribui as dificuldades enfrentadas pelo primeiro contingente na UNIFIL à falta de tradição brasileira em empregar tropas em operações reais, de guerra. E sublinha que o estereótipo do brasileiro no exterior (vinculado ao futebol, carnaval, cordialidade etc.) dificulta, em um primeiro momento, o reconhecimento da capacidade profissional dos militares brasileiros por parte dos militares europeus e estadunidenses (Entrevista II 20I6).

A posição do Brasil como um país intermediário na arena internacional fica evidente quando os entrevistados comparam a percepção dos europeus sobre a capacidade profissional dos militares brasileiros com a percepção que as forças armadas sul-americanas têm sobre esse atributo. Um militar que esteve a frente de um pelotão de combate no segundo contingente brasileiro no Haiti relata que, nas ações das quais participou, os militares dos demais países sul-americanos esperavam e reconheciam a liderança brasileira (Entrevista III 20I6).

Os relatos acima revelam uma grande afinidade entre a identidade internacional do Brasil construída durante as gestões do presidente Lula da Silva $^{\mathrm{T} 4} \mathrm{e}$ a experiência dos militares em tropas internacionais: os militares brasileiros estariam representando um país emergente que buscava qualificar-se como provedor de paz perante a ONU.

Já no que se refere aos reflexos da participação dos militares brasileiros em missões de paz para as relações civis-militares, é possível identificar que, em um primeiro momento, a decisão do governo de Lula da Silva de enviar tropas para o Haiti foi vista com desconfiança por uma parcela da oficialidade.

Um oficial superior que trabalha no Comando de Operações Terrestres do Exército (COTER) relatou que quando o presidente Lula (líder do então maior partido político de esquerda na América Latina) decidiu aceitar o convite da ONU para assumir o comando militar da missão das Nações Unidas no Haiti isso foi interpretado como uma tentativa de afastar as Forças Armadas brasileiras de suas atividades subsidiárias do país, já que o Brasil ainda

I4 A este respeito ver: Amorim (20I6). 
participava, com um contingente menor, da missão de paz no Timor Leste (Entrevista IV 20I6).

Neste contexto, enviar tropas para missões em dois lugares distantes parecia ser parte de uma estratégia do governo do Partidos dos Trabalhadores de tentar controlar os militares mantendo-os em missões no exterior como prescreveu Michael Desch (I999). Mas esta percepção inicial logo se esmaeceu. Com o decorrer do tempo ficou claro que nos governos petistas as Forças Armadas continuariam atuando sistematicamente em missões subsidiárias no território nacional (Mathias, Campos e Santos 20I6) sem perderem sua capacidade de influência e prestígio junto a uma parcela da sociedade brasileira, como ficou evidente durante a greve dos caminhoneiros em maio de 2018 .

Aliás, a atuação rotineira das forças armadas em atividades subsidiárias, não é vista como um ativo importante apenas pela classe política brasileira. O processo de recrutamento dos generais que comandaram o contingente militar da MINUSTAH evidencia que a experiência prévia desses profissionais em operações de Garantia da Lei e da Ordem, de combate a crimes transnacionais e ações de assistência humanitária também é apreciada pela ONU.

Com exceção do general Heleno Pereira, que foi o primeiro force commander brasileiro no Haiti ${ }^{15}$, os demais generais que o sucederam passaram por um processo de seleção na ONU onde a capacidade de lidar com situações de natureza policial e política, que extrapolam a esfera militar, era aferida. O general Ajax Pinheiro, último force commander da MINUSTAH, relata que na entrevista com os funcionários da ONU, antes de assumir o comando da missão, ele procurou relacionar a experiência que teve no comando da Brigada em Cascavel com as atividades que desempenharia no Haiti (Pinheiro 20I8).

O processo seletivo dos force commanders para a MINUSTAH revela que a própria natureza da missão contribuiu fortemente para reforçar a conexão Porto Príncipe-Rio de Janeiro. No entanto, um ponto em comum perpassa o discurso de todos os generais brasileiros que estiveram no Haiti. Quando perguntados se era mais adequado que as Forças Armadas utilizassem o que aprenderam no Haiti em operações de Garantia da Lei e da Ordem ou em outras missões de paz todos afirmam que o aprendizado da MINUSTAH deveria ser replicado em outras missões de paz e não no Brasil. Na visão dos force commanders, a utilização frequente de tropas militares para o combate à criminalidade é um sinal de que o país tem problemas sérios na área de se-

I5 O general Heleno Pereira foi o único nome indicado pelo governo brasileiro para assumir o comando militar da MINUSTAH mas esta não é a prática vigente na ONU. As normas da organização preveem que o país indique alguns profissionais e a ONU selecione aquele que considerar mais capacitado para assumir a função.

256 Austral: Revista Brasileira de Estratégia e Relações Internacionais v.7, n.14, Jul./Dez. 2018 
gurança pública e deve superá-los através do aperfeiçoamento das instituições policiais.

Em entrevista à revista Piauí, o general Villas- Bôas definiu da seguinte forma sua percepção a respeito do emprego do Exército no complexo de favelas da Maré, onde uma parcela importante do contingente militar que esteve no Haiti foi empregado:

"Eram onze horas da manhã ou meio-dia de um dia normal. E o nosso pessoal, muito atento, muito preocupado, muito crispado e armado, estava patrulhando a rua onde passavam mulheres e crianças. Falei: 'Somos uma sociedade doente. O Exército está apontando armas para brasileiros.' Isso é terrível (Victor 20I8)."

Esta entrevista foi concedida depois de o governo federal haver decretado uma intervenção na área de segurança pública no estado do Rio de Janeiro, no início de 2018 , logo não é possível afirmar que a intervenção federal tenha modificado a percepção negativa do Exército brasileiro a respeito da banalização das operações de Garantia da Lei e da Ordem. Por outro lado, é possível afirmar que a banalização das operações de Garantia da Lei e da Ordem evidencia de forma contundente o quanto o presidente Temer depende politicamente do apoio das Forças Armadas para governar.

\section{Considerações finais}

A utilização cada vez mais frequente das Forças Armadas em operações de Garantia da Lei e da Ordem no Brasil exige uma reflexão mais estruturada acerca das conexões existentes entre a participação de tropas brasileiras em operações de paz e em atividades subsidiárias no país. A literatura recente que analisa a atuação brasileira em missões de paz oferece alguns insights interessantes sobre as consequências desta experiência entrecruzada para as relações civis-militares.

Os benefícios da participação do Brasil em missões de paz são inegáveis. Entretanto a forma como a classe política vem processando essa experiência é preocupante. Percebe-se uma clara reversão de expectativas no que diz respeito ao papel que as Forças Armadas brasileiras deveriam desempenhar em um país que pretende assumir uma posição de protagonismo em seu entorno estratégico. Ao invés de contribuir para o aperfeiçoamento da articulação entre a política externa e a política de defesa, a participação das tropas brasileiras em operações de paz tem contribuído para a militarização 
da segurança pública e a policialização das forças armadas.

O elevado grau de dependência do governo Temer em relação às instituições militares pode desencadear também um processo de politização das forças armadas, revertendo um padrão de relações civis-militares que está sendo construído desde a presidência de Fernando Collor, através de reformas institucionais como a diminuição dos ministérios ocupados por militares e a criação do Ministério da Defesa (Oliveira 2005).

Espera-se que os próximos governos utilizem o aparelho militar com mais cautela e em consonância com os interesses da sociedade brasileira. As consequências da utilização política das forças armadas já foram bastante estudadas pela literatura que analisou a ditadura militar no país (Oliveira 1994) e sabe-se que elas são desastrosas para a sociedade, para a classe política e para as instituições militares.

\section{REFERÊNCIAS}

Abdenur, Adriana Erthal et al. "Análises da academia e experiências da sociedade civil brasileira". 20I7. In A participação do Brasil na MINUSTAH (2004-2017): percepções, lições e práticas relevantes para futuras missões, edited by Eduarda Passarelli Hamann and Carlos Augusto Ramires Teixeira. Coletânea de artigos. Rio de Janeiro: Instituto Iguarapé; Centro Conjunto de Operações de Paz do Brasil.

Alsina Júnior, João Paulo S. 20I7. "Grand Strategy and Peace Operations: the Brazilian Case". Revista Brasileira de Politica Internacional, 6o (2):eoo4.

Amorim, Celso. 2016. A grande estratégia do Brasil: discursos, artigos e entrevista da gestão no Ministério da Defesa (2011-2014). Brasília; São Paulo: FUNAG; Editora da UNESP.

Betim, Felipe. 20I8. "Caminhoneiros dobram a aposta e amplificam pedidos por 'intervenção militar'." El País Brasil. Acesso em 29 maio 20I8. https://brasil.elpais.com/brasil/20I8/05/28/politica/1527542536_679526.html.

Brasil. 20I7. Câmara dos Deputados. Comissão de Relações Exteriores e Defesa Nacional. CREDN destaca papel do Brasil no Comando da missão da ONU no Haiti. Acesso em: 03 mar. 20I8. http://www2.camara.leg. br/atividade-legislativa/comissoes/comissoes-permanentes/credn/ noticias/credn-destaca-papel-do-brasil-no-comando-da-missao-daonu-no-haiti. 
2018. Decreto n. 9.382, de 25 de maio de 2018. Acesso em: 26 mai. 20I8. http://www2.planalto.gov.br/acompanhe-planalto/noticias/2018/05/inpdfviewer-I.pdf

Brigagão, Clóvis. I999. "Prevenir, Manter e Construir a Paz: Novos Desafios à Segurança Internacional” In O Brasil e as Novas Dimensões da Segurança Internacional, organized by Gilberto Dupas and Tullo Vigevani. São Paulo: Alfa e Ômega.

Caforio, Giuseppe. 2007. "Trends and evolution in the military profession". In Social Sciences and the Military: An interdisciplinary overview, edited by Giuseppe Caforio. London: Routeledge.

Castro, Celso. 2002. A invenção do Exército brasileiro. Rio de Janeiro: J. Zahar. Cezne, Eric. 20I6. Harnessing the Blue Helmet Enterprise: Brazil, MINUSTAH and the projection of a peacekeeping profile. Dissertação (Mestrado em Relações Internacionais). Departament of International Environment and Development Studies, Norwegian University of Life Sciences.

D’Araújo, Maria Celina. 20ıo. Militares, Democracia e Desenvolvimento: Brasil e América do Sul. Rio de Janeiro: Editora FGV.

Desch, Michael. I999. Civilian Control of the Military: The Changing Security Environment. Baltimore: John Hopkins University Press.

Dwyer, Maggie. 20I5. "Peacekeeping abroad, trouble making at home: mutinies in West Africa". African Affairs, II4 (455): 206-225.

Entrevista I. 20I6. [I7 mai.] Entrevistadoras: Adriana A. Marques e Sílvia Monnerat. Rio de Janeiro. Grupo focal.

Entrevista II. 20I6. [I7 mai.] Entrevistadoras: Adriana A. Marques e Sílvia Monnerat. Rio de Janeiro. Grupo focal.

Entrevista III. 20I6. [I7 mai.] Entrevistadoras: Adriana A. Marques e Sílvia Monnerat. Rio de Janeiro. Grupo focal

Entrevista IV. 20I6. [mar.] Entrevistadora: Adriana A. Marques. Brasília. Informação verbal.

Haring, Christoph. 20I5. "Synergy effects between MINUSTAH and public security in Brazil". Brasiliana: Journal for Brazilian Studies, 3 (2): I42I68.

Góes, Bruno. 20I8. Brasil desiste de participar de missão de paz na República Centro-Africana. O Globo. Acesso em: Io abr. 20I8. https://oglobo.globo.com/mundo/brasil-desiste-de-participar-de-missao-de-paz-na-republica-centro-africana-22573896.

Hirst, Mónica and Nasser, Reginaldo Mattar Nasser. 20I4. Brazil's involvement in peacekeeping operations: the new defence security foreign policy nexus. 
Oslo: Norwegian Peacebuilding Resource Centre. . 20I6. "El marco multilateral y la presencia regional en Haiti". In La presencia de Argentina en Haití: contexto global, regional y experiencia militar (2004-2015), edited by Sabina Frederic and Mónica Hirst. Ciudad Autónoma de Buenos Aires: Teseo.

Hoelscher, Kristian, Norheim Martinsen, Per M. 20I4. "Urban violence and the militarisation of security: Brazilian "peacekeeping" in Rio de Janeiro and Port au Prince”. Small Wars \& Insurgencies, 25 (5-6): 957975 .

Janowitz, Morris. I967. O soldado profissional: estudo social e político. São Paulo: GRD.

Jungmann, Raul. Encerramento da participação brasileira na MINUSTAH. Rio de Janeiro, 2I de outubro de 20I7. Acesso em: 03 mar. 2018. https://www.defesa.gov.br/arquivos/20I7/pronunciamento/outubro/20I7IO2I_encerramento_haiti.pdf.

Levin, Jamie et al. 20I7. A Test of the Democratic Peacekeeping Hypothesis: Coups, Democracy, and Foreign Military Deployments. Acesso em: 03 mai. 20I8. http://individual.utoronto.ca/sealey/utorweb/Papers_files/A. Sealey-ATestOfTheDPH-20I7.pdf.

Lundgren, Magnus. "Backdoor peacekeeping: Does participation in UN peacekeeping reduce coups at home?". Journal of Peace Research, Forthcoming, fev. 2018.

Marques, Adriana. A. 2007. Amazônia: pensamento e presença militar. Tese (Doutorado em Ciência Política). Departamento de Ciência Política da Faculdade de Filosofia e Ciências Humanas, Universidade de São Paulo, Brasil.

Marques, Adriana. A. and Alexandre Fuccille. 2015. "Ensino e Pesquisa em Defesa no Brasil: estruturação do campo e desafios". Revista Brasileira de Estudos de Defesa, 2 (2): 53-69.

Matei, Florina Cristiana. 20I2. "A New Conceptualization of Civil-Military Relations". In The Routledge Handbook of Civil-Military Relations, organized by Thomas C. Bruneau and Florina Cristiana Matei. Nova York: Routledge.

Mathias, Suzeley Kalil, Bruce Scheidl Campos and Leandro Fernandes Sampaio Santos. 20i6. Política militar del Gobierno de Rousseff: refexiones sobre la actuación de las Fuerzas Armadas en las UPP y la MINUSTAH. Íconos: Revista de Ciencias Sociales, 55:Ir5-I38.

Monteiro, Tânia. 20I8. "Entrevista com Eduardo Villas Bôas, comandante 
do Exército". O Estado de S. Paulo. Acesso em: I5 jan. 20I8. https:// brasil.estadao.com.br/noticias/geral,contaminacao-de-tropas-federais-por-faccoes-criminosas-preocupa,70002150858.

Moskos, Charles C. 1976. Peace Soldiers: the Sociology of United Nations Military Forces. Chicago: Chicago University Press.

Moskos, Charles C., John Allen Williams and David R. Segal. 2000. The Postmodern Military: Armed Forces after the Cold War. Oxford: Oxford University Press.

Okado, Giovanni Hideki Chinaglia. 20I7. “A Comissão de Relações Exteriores e Defesa da Câmara dos Deputados e a MINUSTAH: entre a resistência inicial e a abdicação". In A participação do Brasil na MINUSTAH (2004-2017): percepções, lições e práticas relevantes para futuras missões, edited by Eduarda Passarelli Hamann and Carlos Augusto Ramires Teixeira. Coletânea de artigos. Rio de Janeiro: Instituto Iguarapé; Centro Conjunto de Operações de Paz do Brasil.

2005. Democracia e defesa nacional: a criação do Ministério da Defesa na presidência de FHC. Barueri: Manole.

Oliveira, Eliézer Rizzo. I994. De Geisel a Collor: forças armadas, transição e democracia. Campinas, SP: Papirus.

Pinheiro, Ajax Porto. 20I8. Ajax Porto Pinheiro: depoimento [30 jan.] Entrevistadores: Celso Castro e Adriana A. Marques. Brasília. Depoimento concedido ao projeto Transformações da profissão militar no Brasil e na Argentina: a perspectiva das Ciências Sociais.

Pion-Berlin, David and Craig Arceneaux,. 2000. "Decision Maker or Decision Takers? Military Missions and Civilian Control in Democratic South America". Armed Forces and Society, 26 (3): 4I3-426.

Pion-Berlin, David and Harold Trinkunas. 2007. "Attention Deficits: Why Politicians Ignore Defense Policy in Latin America". Latin American Research Review, 42 (3): 76-100.

. Cumprimento de missões militares na América Latina. Varia Historia, 28 (48): 627-643.

Siman, Maíra and Victória Santos. 2018. "Interrogating the security-development nexus in Brazil's domestic and foreign pacification engagements". Conflict, Security Q Development, I8 (I): 6I-83.

Sotomayor, Arturo C. 20I4. The Mith of Democratic Peacekeeper: Civil-Military Relations and United Nations. Baltimore: John Hopkins University Press.

Teixeira, Carlos Augusto Ramires. “Centro Conjunto de Operações de Paz do 
Brasil: história e perspectivas pós-MINUSTAH”. In A participação do Brasil na MINUSTAH (2004-2017): percepções, lições e práticas relevantes para futuras missões, edited by Eduarda Passarelli Hamann and Carlos Augusto Ramires Teixeira. Coletânea de artigos. Rio de Janeiro: Instituto Iguarapé; Centro Conjunto de Operações de Paz do Brasil.

Victor, Fabio. 2018. "Mal-estar na caserna". Revista Piauí. Acesso em: Io mar. 20I8. http://piaui.folha.uol.com.br/materia/mal-estar-na-caserna/\#.

Zaverucha, Jorge. 2005. FHC, Forças armadas e polícia: entre o autoritarismo e a democracia (1999-2002). Rio de Janeiro: Record.

. 2008. "The Guaranteeing Law and Order Doctrine and the Increased Role of the Brazilian Army in Activities of Public Security". Nueva Sociedad, 213. Acesso em: o8 mai 20I8. http://nuso.org/media/articles/ downloads/3498_2.pdf.

\section{RESUMO}

$\mathrm{O}$ artigo discute as interconexões entre a participação dos militares brasileiros em missões de paz e as relações civis-militares no país. Para sua elaboração foi realizada uma revisão bibliográfica e a coleta de fontes primárias, como documentos governamentais, matérias publicadas em jornais e revistas e entrevistas. Conclui-se que ao invés de contribuir para o aperfeiçoamento da articulação entre a política externa e a política de defesa, a participação brasileira em operações de paz vem sendo instrumentalizada pela classe política e contribuindo indiretamente para a militarização da segurança pública e a policialização das forças armadas.

\section{PALAVRAS-CHAVE}

Missões de Paz; Relações Civis-Militares; Garantia da Lei e da Ordem 